\title{
Preparation and Performance Evaluation of Reforming Prehydrogenation Catalyst Used for Blending Inferior Coking Gasoline
}

\author{
Tiezhen Zhang*, Yungang Jia, Famin Sun, Liang Wang, Wei Jiang, Fucun Wang, Haiyan Li \\ Petrochina Daqing Petrochenical Research Center, Daqing, Heilongjiang, 163714, China \\ Email: zhangtz459@petrochina.com.cn
}

\begin{abstract}
A reforming prehydrogenation catalyst suitable for blending inferior coking gasoline was developed by the supporter modification, selection and optimization of active component. The catalyst has high performance of hydrodesulfurization, hydrodenitrification and olefin saturation at low temperature. The catalyst has good activity and strong adaptability to raw materials, At reaction pressure of $2.0 \mathrm{MPa}$, hydrogen-oil volume ratio of $200: 1$, LHSV of $5.0 \mathrm{~h}^{-1}$, reaction temperature of $268-280^{\circ} \mathrm{C}$, it can process the prehydrogenation raw materials blending inferior hydrocoking gasoline (20-50\%), and the generated oil can meet the requirements of reforming feed. The results of $1500 \mathrm{~h}$ activity stability test show that the catalyst has excellent activity stability.
\end{abstract}

Keywords: reforming prehydrogenation, coking gasoline, hydrodesulfurization, hydrodenitrification, olefin saturation, catalyst

\section{$1 \quad$ Preface}

Catalytic reforming takes naphtha distillates as raw materials to produce "sulfur-free" high-octane gasoline blended components with low olefin content and/or light aromatic hydrocarbons with high added value, as well as by-product hydrogen. Therefore, catalytic reforming is an indispensable means of producing clean gasoline. In recent years, the catalytic reforming of China obtained a rapid development of technology and equipment ability, but is still a big gap compared with developed countries, there are many factors restricting our enhanced catalytic reforming unit, one of the important reasons is less naphtha in most of the crude oil in China, makes a serious shortage of feedstock, and even make the existing device can only low load operation, so the heavy naphtha of hydrocracking, catalytic gasoline, coking gasoline, etc. as a feedstock for catalytic reforming unit[1-4], is an important way to solve the shortage of catalytic reforming raw oil in China.

Coking gasoline comes from delayed coking unit, which belongs to inferior secondary processing products. Compared with straight run gasoline, the content of sulfur, nitrogen and olefin is high, and the nitrogen content is about 100 times that of straight run gasoline, and the forms of nitrides are more complex. It is difficult to prepare qualified reforming raw materials under the existing reforming prehydrogenation process. For this reason, coking gasoline must be hydrotreated before reforming prehydrogenation in order to meet the requirements of the raw material of reforming hydrogenation[5,6].

In order to alleviate the shortage of raw materials in catalytic reforming unit and solve the outlet of coking gasoline, Petrochina Dagang Petrochemical Company blended the hydrorefined coking gasoline into the straight run gasoline as the reforming raw material. Moreover, the blended ratio should be controlled below $35 \%$, and the high-grade gasoline produced under this ratio will not be affected [7].

This study focuses on the modification technology of the supporter, the selection and optimization of active component, developed a suitable reforming hydrogenation catalyst for blending inferior coking gasoline. The catalytic performance evaluation results show that the catalyst has high performance of hydrodesulfurization, hydrodenitrification and olefin saturation at low temperature, and at the same time. The catalyst has strong adaptability to raw materials and good activity stability. 


\section{$2 \quad$ Materials and Instruments}

\subsection{Reagents and Instruments}

Alumina, industrial grade, content of alumina 65 70\%, Aluminum Corporation of China Limited Shandong branch; Nitric acid, purity of $65 \sim 68 \%$, Tianjin jinke fine chemical research institute; Citric acid, food grade, purity greater than 99.9\%, Tianjin ruijinte chemical co. LTD; Tianjing powder, industrial grade, Jiangsu hongrun plant glue co. LTD; Nickel nitrate, industrial grade, Wuxi xinxing chemical factory; Basic cobalt carbonate, Co content 45.0 50.0\%, Tianjin jinke fine chemical research institute; Ammonium molybdate, $\left(\mathrm{NH}_{4}\right)_{6} \mathrm{Mo}_{7} \mathrm{O}_{24} \cdot 6 \mathrm{H}_{2} \mathrm{O}$ content $99.0 \%$, Tianjin No. 4 chemical reagent factory.

Micromeritics ASAP2010 automatic adsorbent is used to determine the specific surface area, pore volume and pore diameter distribution of supports and catalysts; D/max-III X-ray diffractometer is used for XRD characterization of supporters; Newus (Nicolet, US) infrared spectrometer FT-IR spectrometer is used to determine the IR spectra and the acid position of pyridine after adsorption of the supporters and catalysts.

\section{$2.2 \quad$ Raw Materials of Test}

The raw materials used in the test are straight run naphtha and hydrogenated coking gasoline from Daqing Petrochemical Company. The composition and properties of the raw materials are shown in Table 1.

Table 1. Composition and properties of test materials

\begin{tabular}{|c|c|c|c|c|}
\hline Items & $\begin{array}{c}\text { straight run } \\
\text { naphtha }\end{array}$ & $\begin{array}{c}20 \% \text { coking } \\
\text { gasoline }\end{array}$ & $\begin{array}{c}30 \% \text { coking } \\
\text { gasoline }\end{array}$ & $\begin{array}{c}50 \% \text { coking } \\
\text { gasoline }\end{array}$ \\
\hline $\operatorname{Density}\left(20^{\circ} \mathrm{C}\right), \mathrm{g} / \mathrm{cm}^{3}$ & 0.7261 & 0.7272 & 0.7278 & 0.7284 \\
\hline bromine number, $\mathrm{gBr} / 100 \mathrm{~g}$ & 1.54 & 1.68 & 1.89 & 2.14 \\
\hline sulphur content, $\mu \mathrm{g} / \mathrm{g}$ & 372.45 & 328.86 & 340.57 & 262.34 \\
\hline nitrogen content, $\mu \mathrm{g} / \mathrm{g}$ & 12.23 & 14.26 & 16.18 & 21.83 \\
\hline \multirow{3}{*}{$\begin{array}{l}\text { metal content, } \\
\mathrm{ng} / \mathrm{g}\end{array}$} & 136.18 & 108.94 & 94.56 & 69.56 \\
\hline & 2.18 & 2.05 & 1.93 & 1.69 \\
\hline & 25.86 & 42.85 & 68.13 & 110.32 \\
\hline
\end{tabular}

Table 2. Analysis of hydrogen composition for the test

\begin{tabular}{ccccccc}
\hline composition & $\mathrm{H}_{2}$ & $\mathrm{CH}_{4}$ & $\mathrm{C}_{2} \mathrm{H}_{6}$ & $\mathrm{CO}$ & $\mathrm{N}_{2}$ & analytical method \\
\hline content, $\varphi \%$ & 96.300 & 1.909 & 0.002 & 0.002 & 1.787 & gas chromatographic method \\
\hline
\end{tabular}

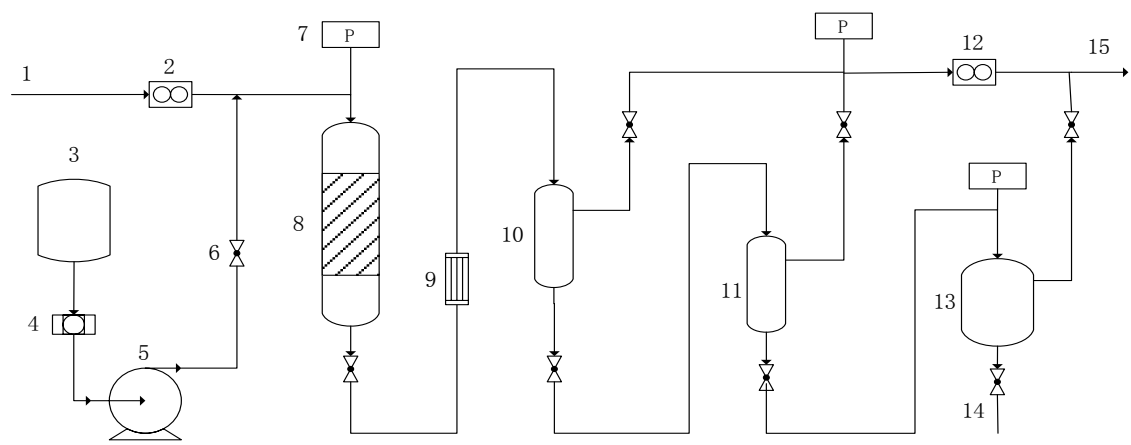

1.Hydrogen 2.Hydrogen flowmeter 3.Stock tank 4.Filter 5.Feed pump 6.Ball check 7.Pressure gauge 8.Reactor 9.Cooler 10.High pressure separator

11.Low pressure separator 12.Tail gas flowmeter 13.Product tank 14.Sampling port 15.Tail gas

Figure 1. Flow diagram of $100 \mathrm{ml}$ hydrogenation evaluation unit 
The hydrogen used in the test is industrial hydrogen from the First Chemical Plant of Daqing Petrochemical Company, and its composition is shown in Table 2.

\subsection{Test Device}

The catalytic performance of the catalyst was evaluated with $100 \mathrm{ml}$ fixed bed hydrogenation test device, as shown in Figure 1.

\section{$3 \quad$ Test Part}

\subsection{Selection of Supporter Materials}

The main factor affecting the catalytic performance is not the total pore volume of the catalyst, but the pore distribution of the catalyst, which depends on the pore distribution of the support. The pore structure of the support affects the performance of the catalyst, and the most direct influence is the pore structure and mechanical strength of catalyst. The pore structure of the supporter must be suitable for the requirements of reforming prehydrogenation, and the mechanical strength must meet the requirements of industrial production. Therefore, the proportion of macropores in the catalyst should be appropriate, which can reduce the speed of coke plugging the catalyst pores and prolong the life of the catalyst. However, the specific surface area should not be too low, which is not conducive to the activity of the catalyst. The physical properties of three kinds of pseudo boehmite (No.1, No.2 and No.3) are listed in Table 3.

Table 3. Comparison of physical properties of three pseudo boehmite

\begin{tabular}{cccc}
\hline Analysis project & No.1 & No.2 & No.3 \\
\hline specific surface area, $\mathrm{m}^{2} / \mathrm{g}$ & 407 & 355 & 281 \\
pore volume, $\mathrm{ml} / \mathrm{g}$ & 0.95 & 0.78 & 0.63 \\
average pore size, $\AA$ & 48 & 45 & 37 \\
\hline
\end{tabular}

It can be seen that the pore volume and pore size of No. 2 and No. 3 are relatively small, which is not conducive to the diffusion of reaction molecules or the long-term operation of catalyst; the pore size and pore volume of No. 1 are relatively large, which is conducive to the diffusion of reaction molecules, so that the catalyst has a larger anti-coking capacity; the large specific surface area is also conducive to the improvement of catalyst activity. Therefore, it is ideal to choose No. 1 pseudo boehmite.

\subsection{Preparation of Supporter}

Crush No. 1 pseudo boehmite and other solid materials to a certain mesh, add a proper amount of glue solvent, extrusion aid, adhesive, deionized water and mix them evenly, and extrude them into clover type. The composite supporter was prepared by drying at $120{ }^{\circ} \mathrm{C}$ for 4 hours and calcinating at $500{ }^{\circ} \mathrm{C}$ for 4 hours.

\subsection{Introduction of Supporter Modifier}

The purpose of reforming prehydrofining is to remove sulfur, nitrogen, oxygen compounds and other toxic substances of reforming catalyst, such as arsenic, lead, copper, mercury, sodium, etc. from reforming feed oil, so as to protect reforming catalyst. Because the raw materials contain a certain amount of olefins and arsenic, which are not completely removed, it is easy to make the catalyst coking and deactivation. Therefore, in the development of the catalyst, the IVB transition metal is introduced into the support molding, which can adjust the acid-base property of the support, inhibit the coking and deactivation speed of the catalyst, and improve the anti-coking performance.

The main purposes of modifying the supporter by introducing additives are: (1) adjusting the surface chemical properties, weakening the interaction between metal and supporter; (2) optimizing the dispersion 
state of active components; (3) promoting the vulcanization of active components; (4) changing the type and distribution of active centers.

In the process of supporter forming with pseudo boehmite No.1, two compounds D-1 and D-2 containing modifier metal $\mathrm{D}$ are introduced as modifiers. $\mathrm{D}$ metal does not enter into the lattice of $\gamma-\mathrm{Al}_{2} \mathrm{O}_{3}$, so it does not change the structure of $\gamma-\mathrm{Al}_{2} \mathrm{O}_{3}$, but forms a strong interaction with $\gamma-\mathrm{Al}_{2} \mathrm{O}_{3}$. Because of the strong interaction between the modifier and the support alumina, the interaction between the metal and the support alumina is weakened, the reaction temperature of the catalyst is reduced, and the hydrodesulfurization performance is improved. The physical and chemical properties of the supporter are shown in Table 4, and the infrared acid analysis is shown in Table 5.

Table 4. Physical and chemical properties of supporter

\begin{tabular}{cccccc}
\hline Sample name & $\begin{array}{c}\text { specific surface } \\
\text { area, } \mathrm{m}^{2} / \mathrm{g}\end{array}$ & $\begin{array}{c}\text { pore volume, } \\
\mathrm{ml} / \mathrm{g}\end{array}$ & $\begin{array}{c}\text { average pore } \\
\text { size, } \AA\end{array}$ & $\begin{array}{c}\mathrm{D} \\
\omega \%\end{array}$ & $\begin{array}{c}\mathrm{Al}_{2} \mathrm{O}_{3} \\
\omega \%\end{array}$ \\
\hline supporter modified by D-1 & 244 & 0.59 & 47.4 & 19.49 & allowance \\
supporter modified by D-2 & 277 & 0.65 & 46.2 & 20.00 & allowance \\
\hline
\end{tabular}

Table 5. Supporter infrared acid analysis data

\begin{tabular}{cccc}
\hline Sample name & & B-acid & L-acid \\
\hline \multirow{2}{*}{ supporter modified by D-1 } & $\left(150^{\circ} \mathrm{C}\right)$ & 0 & 0.317 \\
& $\left(350^{\circ} \mathrm{C}\right)$ & 0 & 0.091 \\
\hline \multirow{2}{*}{ supporter modified by D-2 } & $\left(150^{\circ} \mathrm{C}\right)$ & 0 & 0.438 \\
& $\left(350^{\circ} \mathrm{C}\right)$ & 0 & 0.152 \\
\hline
\end{tabular}

From the analysis results in Table 4 and Table 5, it can be seen that the specific surface area, pore volume and L-acid of supporter modified by D-2 are all larger than those of supporter modified by D-1.

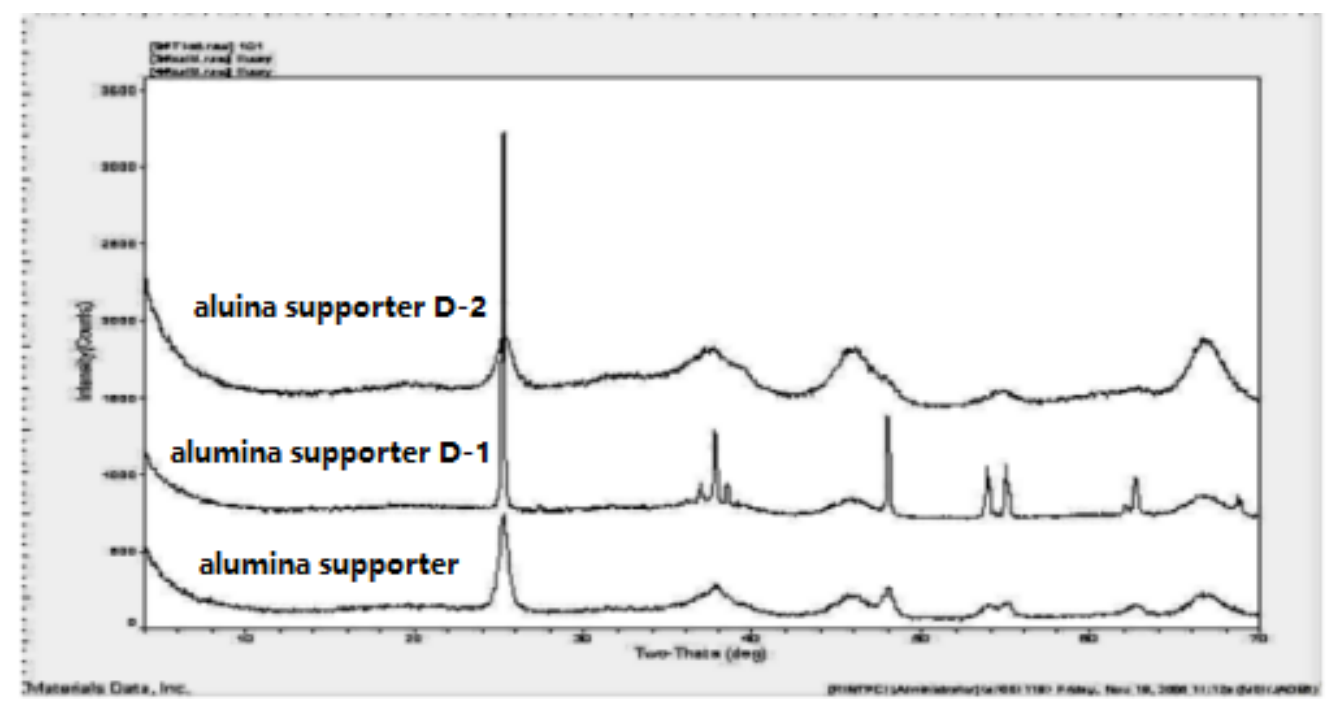

Figure 2. XRD spectra of two modified supporters by different methods

As can be seen from Figure 2, the characteristic peak strength of the supporter modified by D-2 is the weakest, and the spectral peak is close to that of alumina supporter, which indicates that the particle size of the supporter modified by D-2 is the smallest. The modified additives disperse evenly, the utilization rate of modified additives is highest. Therefore, D-2 was selected as the supporter modification additive. 


\subsection{Selection of Active Components}

For reforming prehydrogenation catalyst, the active metal components widely used are Mo, W, Co and Ni, in which: (1) W-Ni and Mo-Ni systems: suitable for deep hydrogenation denitrification and aromatic saturation reaction under medium and high pressure conditions; (2) Mo-Co system: it is suitable for hydrodesulfurization reaction under low pressure; (3) Mo-Co-Ni system: compared with the above systems, $\mathrm{Ni}$ is introduced into the Mo-Co system, It has higher hydrodesulfurization activity, and at the same time, the reactions of alkene saturation, hydrodenitrification and arsenic removal were considered. It is more suitable for the prehydrogenation process of reforming under the condition of moderating process. Therefore, Mo-Co-Ni system was selected as the active metal system for the catalyst.

\subsection{Preparation of Catalyst}

The metal co-leaching solution was prepared by ammonium molybdate, basic cobalt carbonate and nickel nitrate in a certain proportion. The supporter modified by D-2 was co-impregnated for 1 hour by saturated impregnation method, then dried at $120^{\circ} \mathrm{C}$ for 4 hours, then calcinated at $500^{\circ} \mathrm{C}$ for 4 hours, and the catalyst was prepared.

\subsection{Physical and Chemical Properties Analysis of Catalyst}

The physical and chemical properties of the catalyst including composition, specific surface area, pore structure, acidity and strength were analyzed. The results are shown in Table 6.

Table 6. Physicochemical properties of catalyst

\begin{tabular}{cc}
\hline Analysis project & Data \\
\hline $\mathrm{Al}_{2} \mathrm{O}_{3}, \omega \%$ & 66.81 \\
$\mathrm{MoO}_{3}, \omega \%$ & 16.38 \\
$\mathrm{Co}_{2} \mathrm{O}_{3}, \omega \%$ & 2.89 \\
$\mathrm{NiO}, \omega \%$ & 1.94 \\
$\mathrm{D}$ modifier, $\omega \%$ & 11.98 \\
pore volume, $\mathrm{ml} / \mathrm{g}$ & 0.37 \\
average pore size, $\AA$ & 40.8 \\
specific surface area, $\mathrm{m}^{2} / \mathrm{g}$ & 197.8 \\
B-acid $\left(150^{\circ} \mathrm{C} / 350^{\circ} \mathrm{C}\right)$ & $0.033 / 0$ \\
L-acid $\left(150^{\circ} \mathrm{C} / 350^{\circ} \mathrm{C}\right)$ & $0.469 / 0.168$ \\
strength, $\mathrm{N} / \mathrm{mm}$ & 16.2 \\
\hline
\end{tabular}

Table 7. Evaluation results of catalyst activity and material adaptability

\begin{tabular}{ccccccccc}
\hline & \multicolumn{7}{c}{ Analysis data of hydrogenated oil } \\
\cline { 2 - 8 } Raw materials & $\begin{array}{c}\text { reaction } \\
\text { temperature, } \\
\end{array}$ & $\begin{array}{c}\text { Density } \\
\left(20^{\circ} \mathrm{C}\right), \\
\mathrm{g} / \mathrm{cm}^{3}\end{array}$ & $\begin{array}{c}\text { sulfur } \\
\text { content, } \\
\mu \mathrm{g} / \mathrm{g}\end{array}$ & $\begin{array}{c}\text { nitrogen } \\
\text { content, } \\
\mu \mathrm{g} / \mathrm{g}\end{array}$ & $\begin{array}{c}\mathrm{Cu}, \\
\mathrm{ng} / \mathrm{g}\end{array}$ & $\begin{array}{c}\mathrm{Pb}, \\
\mathrm{ng} / \mathrm{g}\end{array}$ & $\begin{array}{c}\text { As, } \\
\mathrm{ng} / \mathrm{g}\end{array}$ & $\begin{array}{c}\text { bromine } \\
\text { value, } \\
\mathrm{gBr} / 100 \mathrm{~g}\end{array}$ \\
\hline straight run naphtha & 263 & 0.7262 & 0.38 & 0.18 & 0.31 & 0.22 & 0.38 & 0.003 \\
$20 \%$ coking gasoline & 268 & 0.7268 & 0.45 & 0.21 & 0.34 & 0.29 & 0.41 & 0.005 \\
$30 \%$ coking gasoline & 274 & 0.7271 & 0.41 & 0.42 & 0.33 & 0.31 & 0.42 & 0.004 \\
$50 \%$ coking gasoline & 280 & 0.7275 & 0.38 & 0.47 & 0.31 & 0.33 & 0.45 & 0.005 \\
\hline
\end{tabular}




\section{Performance Evaluation Results and Discussion of Catalyst}

\subsection{Catalyst Activity and Material Adaptability Evaluation Test}

Under the conditions of reaction pressure of $2.0 \mathrm{MPa}$, LHSV of $5.0 \mathrm{~h}^{-1}$ and hydrogen-oil volume ratio of 200:1, the catalyst activity and material adaptability test were carried out, and the test results are shown in Table 7 .

It can be seen from Table 7 that the hydrogenation product of straight run naphtha raw material at $263^{\circ} \mathrm{C}$ can meet the requirements of reforming feed, and the catalyst developed has better performance of low-temperature hydrodesulfurization, denitrification and olefin saturation. As with the increase of the proportion of coking gasoline in raw material, the reaction temperature required for the prehydrogenation products to meet the requirements of reforming raw materials is also gradually increasing. Under the $268^{\circ} \mathrm{C}$, the hydrogenation products of coking gasoline containing $20 \%$ of the raw material can meet the requirements of reforming feed, and coking gasoline containing $50 \%$ of the raw material under the $280{ }^{\circ} \mathrm{C}$ hydrogenation products can meet the requirements of reforming feed. The experiment shows that the catalyst has strong adaptability, and it is feasible to expand the source of reforming raw materials by adding inferior hydrogenated coking gasoline into the straight run naphtha by strengthening the operation conditions of reforming prehydrogenation.

\subsection{Activity Stability Test of Catalyst}

The activity stability test of the catalyst was carried out with $50 \%$ coking gasoline as raw material at $280^{\circ} \mathrm{C}$, pressure of $2.0 \mathrm{MPa}$, hydrogen-oil volume ratio of $200: 1$ and LHSV of $5.0 \mathrm{~h}^{-1}$. The test results are shown in Table 8.

Table 8. Results of $1500 \mathrm{~h}$ stability test

\begin{tabular}{ccccccc}
\hline $\begin{array}{c}\text { Operation time, } \\
\mathrm{h}\end{array}$ & $\begin{array}{c}\text { sulfur content, } \\
\mu \mathrm{g} / \mathrm{g}\end{array}$ & $\begin{array}{c}\text { nitrogen content, } \\
\mu \mathrm{g} / \mathrm{g}\end{array}$ & $\begin{array}{c}\text { bromine value, } \\
\mathrm{gBr} / 100 \mathrm{~g}\end{array}$ & $\begin{array}{c}\mathrm{Cu}, \\
\mathrm{ng} / \mathrm{g}\end{array}$ & $\begin{array}{c}\mathrm{Pb}, \\
\mathrm{ng} / \mathrm{g}\end{array}$ & $\begin{array}{c}\mathrm{As}, \\
\mathrm{ng} / \mathrm{g}\end{array}$ \\
\hline 200 & 0.44 & 0.41 & 5 & 0.32 & 0.33 & 0.44 \\
400 & 0.42 & 0.42 & 5 & 0.34 & 0.32 & 0.43 \\
600 & 0.45 & 0.42 & 6 & 0.34 & 0.33 & 0.44 \\
800 & 0.43 & 0.43 & 5 & 0.33 & 0.31 & 0.44 \\
1000 & 0.46 & 0.43 & 5 & 0.31 & 0.33 & 0.45 \\
1200 & 0.44 & 0.44 & 6 & 0.32 & 0.34 & 0.43 \\
1400 & 0.43 & 0.43 & 7 & 0.34 & 0.33 & 0.43 \\
1500 & 0.45 & 0.45 & 6 & 0.33 & 0.34 & 0.44 \\
\hline
\end{tabular}

According to the results in Table 8, under the condition that no temperature was raised during the $1500 \mathrm{~h}$ activity stability test, the sulfur and nitrogen contents of the generated oil were all less than 0.5 $\mu \mathrm{g} / \mathrm{g}$, and the bromine value was less than $0.01 \mathrm{gBr} / 100 \mathrm{~g}$. The product properties did not change much during the activity stability test, indicating that the activity of the catalyst was hardly weakened and the catalyst had good activity stability.

\section{Conclusions}

(1) A reforming prehydrogenation catalyst $\mathrm{Mo}-\mathrm{Co}-\mathrm{Ni} / \mathrm{Al}_{2} \mathrm{O}_{3}-\mathrm{D}$ was successfully developed, which was suitable for blending inferior coking gasoline. The support was made of pseudo-boehmite with appropriate pore structure and specific surface area, and modified by D-2;

(2) The reforming prehydrogenation catalyst Mo-Co-Ni/ $\mathrm{Al}_{2} \mathrm{O}_{3}-\mathrm{D}$ has high low-temperature desulfurization, denitrification and olefin saturation performance. At reaction pressure of 2.0MPa, hydrogen-oil volume ratio of $200: 1$, LHSV of $5.0 \mathrm{~h}^{-1}$, reaction temperature of $268-280^{\circ} \mathrm{C}$, it can process the prehydrogenation raw 
materials blending inferior hydrocoking gasoline (20-50\%), and the generated oil can meet the requirements of reforming feed.

(3) The results of $1500 \mathrm{~h}$ activity stability test show that the catalyst has good activity stability.

\section{References}

1. Qun Guo,Jianwei Dong,Yulin Shi. Hydro-genation of straight-run naphtha blended with FCC naphtha for reforming feedstock. [J]Petroleum Processing and Petrochemicals,2003,34(6):10-13.

2. Lishun Dai, Jinhua Qu, Jianwei Dong,et al.Study on hydrotreating of FCC naphtha for catalytic reforming feed stock.[J].Petrochemical Technology \& Application,2005,23(4):267-270.

3. Xiaolu Wang.Industrial test of hydrogenated coking gasoline as reforming feedstock[J]. Petro-leum Processing and Petrochemicals,2000,31(2):13-16.

4. Fushan Jiang, Qiang Cui, Xuejun Huang.Technical analysis of reforming raw materials for hydrogenation production of coking gasoline[J]. Petroleum Processing and Petrochemicals,2003,34(1):61-63.

5. Jian Qin.Catalytic reforming feedstock from coking gasoline hydrogenation[J]. Anqing petrochemical, 1999, 21(2) $4-6$.

6. Yongan Li,Guohong Huang,Qingsong shan. Continuous reforming mixing refined coking gasoline[J].Petroleum Processing and Petrochemicals,2000,31(11):15-17.

7. Lin Wang. Straight run gasoline mixed with coking hydrogenated gasoline as reforming raw material[J].Inner Mongolia petrochemical industry,2007,9:147-148. 